\title{
Assessing the Validity of Bioelectrical Impedance and Skinfold Calipers for Measuring Body Composition in NOLS Backcountry Hikers
}

\author{
Jihan K. Boughman, MS, RDN ${ }^{1}$; Melissa A. Masters, $\mathrm{PhD}, \mathrm{RDN}^{2}$; Cass A. Morgan, $\mathrm{PhD}^{3}$; \\ Tim M. Ruden, $\mathrm{MS}^{3}$; Shannon G. Rochelle, $\mathrm{MS}^{4}$ \\ ${ }^{1}$ Department of Food Science and Human Nutrition, Colorado State University, Boulder, CO; ${ }^{2}$ Department of Human Nutrition, Metropolitan State Uni- \\ versity of Denver, Denver, CO; ${ }^{3}$ Department of Health Promotion and Human Performance, Weber State University, Ogden, UT; ${ }^{4}$ The National Outdoor \\ Leadership School, Lander, WY
}

\begin{abstract}
Introduction-The National Outdoor Leadership School (NOLS) conducts backcountry research in an effort to provide the most up-to-date support to its students. Past research efforts have used a variety of body composition measurement tools, including bioelectrical impedance (BIA), skinfold calipers, and air displacement plethysmography (Bod Pod), but these tools are not interchangeable. The purpose of this study was to determine the feasibility and accuracy of the Tanita scale and the Harpenden skinfold calipers for assessing body composition in backcountry hikers.

Methods-Twenty-two NOLS participants completed a 23-d backpacking trip into the Wind River Range in Wyoming. Pre- and postexpedition anthropometric measures were collected using 3 different body composition measurement tools: Tanita segmental body composition monitor, Harpenden skinfold calipers, and the Bod Pod. For the purposes of this study, the Bod Pod was used as the standard against which other methods were compared.

Results-Participants lost a significant amount of weight and fat during the expedition. Fat-free mass increased by $0.4 \pm 1.9 \mathrm{~kg}$, but this did not reach significance. A high degree of reliability was found between skinfold calipers and the Bod Pod and between BIA and the Bod Pod. The BIA measurements significantly underreported body fat percentage when compared to the Bod Pod, whereas the skinfold measurements were not significantly different from the Bod Pod, but measurements were more variable.

Conclusions-This study shows that the skinfold caliper and the Tanita scale give measurements comparable to the less readily available and more costly Bod Pod measurement in backcountry expedition participants.
\end{abstract}

Keywords: National Outdoor Leadership School, intraclass correlation coefficient, backcountry nutrition, exercise physiology, air displacement plethysmography, body fat

\section{Introduction}

Since its founding in 1965, the National Outdoor Leadership School (NOLS) has taken students into the backcountry to provide education about technical outdoor skills,

Presented at the Association for Experiential Education's Symposium on Experiential Education Research in Montreal, Canada on November 11, 2017.

Corresponding author: Jihan K. Boughman, MS, RDN, 2717 Crestridge Ct, Boulder, CO 80302.; e-mail: jihanbough@yahoo.com.

Submitted for publication September 2018.

Accepted for publication June 2019. leadership, and environmental ethics. ${ }^{1}$ Typical expeditions last anywhere from $10 \mathrm{~d}$ to a full academic year, during which time students rely on the food provided by NOLS and the food preparation skills of themselves and their cook mates. Regarding food provisions, NOLS currently uses a bulk rationing system based on the weight of food each person will eat each day (pounds per person per day). ${ }^{2}$ The total amount of food carried is determined by the intensity and duration of the trip and the sizes and ages of participants. ${ }^{2}$ Summer courses in the Wind River Range typically supply 0.7 to $0.8 \mathrm{~kg}$ per person per day $(1.5-1.8 \mathrm{lb})$. NOLS rations are further broken down into 
9 food categories: 1) breakfast; 2) dinner; 3 ) cheese; 4) trail foods; 5) flour and baking; 6) sugar and fruit drinks; 7) soups, bases, and desserts; 8) milk, eggs, butter, and cocoa; and 9) meats and meat substitutes. ${ }^{2}$ Breakfast, dinner, and trail foods each make up approximately 15 to $20 \%$ of the total food weight carried, and all other groups make up $<15 \%$ of total food weight. ${ }^{2}$

Providing NOLS participants with accurate energy and sufficient nutrients plays an essential role in maintaining the health and safety of all expeditioners. During a pilot study undertaken by NOLS in 2010 and 2011, participants consumed significantly fewer calories than expended during an expedition. ${ }^{3}$ In response to these studies and as part of its risk management initiative, NOLS implemented a nutrition program that combines 1) providing energy and nutrient rich foods for expeditions with 2) educating students about the science and strategies related to adequate nutrition during extended expeditions. ${ }^{4}$

NOLS continues to conduct backcountry nutrition research in an effort to provide the best and most up-todate support to its students, with specific emphasis placed on minimizing weight loss and declines in fat-free mass. Monitoring body composition assists in assessing for energy deficit in backcountry expedition participants. Past research efforts ${ }^{3,5}$ have used a variety of body composition measurement tools, including bioelectrical impedance (BIA), skinfold calipers, and air displacement plethysmography (Bod Pod). These tools all provide objective information about body mass (fat, bone, water, and muscle), but as stated in several previous studies, they are not interchangeable, and each method has limitations. ${ }^{6-8}$ Use of body composition tools that are simple, inexpensive, and rapid, yet still valid, is important to field-based researchers and practitioners.

\section{TANITA SCALE}

A BIA analysis uses the electrical properties of body tissue to predict fat-free mass and total body water. ${ }^{9}$ Lean tissue contains more fluid and electrolytes than fat mass and thus is a better electrical conductor. ${ }^{9,10}$ The Tanita scale uses resistance to the flow of electrical current through lean tissue to estimate fat-free mass and total body water. Because of the shape of the human body, measuring body composition segmentally, as 5 cylinders rather than 1 , can yield more accurate results. ${ }^{11}$ The Tanita BC-558 IRONMAN segmental body composition monitor uses single-frequency segmental BIA analysis to calculate body composition. This particular model uses retractable hand grip and feet electrodes to predict weight, body fat, muscle mass, body water percentage, basal metabolic rate, bone mass, and visceral fat.

\section{SKINFOLD CALIPER}

By gripping skin and subcutaneous tissue, calipers are used to predict body composition. The Harpenden skinfold caliper is designed with 2 springs that apply a closing force to the jaws of the caliper at a constant pressure of $10 \mathrm{~g} \cdot \mathrm{mm}^{-2} .^{12}$ The sums of the skinfold readings are entered into prediction equations to predict body density and body fat percentage. $^{12}$

\section{BOD POD}

The only accurate method of measuring body composition is cadaver analysis, although in vivo models, such as air or water displacement plethysmography, have been widely accepted as surrogate methods. ${ }^{7,13,14}$ The Bod Pod is an air displacement plethysmograph that measures mass and volume to calculate body density. The Bod Pod is outfitted with an electronic scale to measure body mass. Body volume is indirectly measured by measuring the volume of the air the body displaces inside of the enclosed chamber of the Bod Pod. ${ }^{15}$ In adiabatic conditions, Poisson's equation $\left(\mathrm{P}_{1} \mathrm{P}_{2}=\left(\mathrm{V}_{1} \mathrm{~V}_{2}\right) \mathrm{r}\right)$ is used to calculate body volume; in isothermic conditions, Boyle's law $\left(\mathrm{P}_{1} \mathrm{~V}_{1}=\mathrm{P}_{2} \mathrm{~V}_{2}\right)$ is used. ${ }^{15}$ Although the Bod Pod functions primarily in adiabatic conditions, isothermic air can become trapped in a subject's clothes, hair, and lungs. ${ }^{15}$ To minimize these isothermic conditions, a swim cap and bathing suit can be worn; to account for air in the lungs, thoracic gas volume can be predicted by calculating surface area artifact (SAA) using the equation $S A A(L)=k\left(L \mathrm{~cm}^{2}\right) \times B S A\left(\mathrm{~cm}^{2}\right) .{ }^{15}$

This study had 2 primary goals; first, to monitor changes in body composition before and after the NOLS backcountry expedition; and second, to determine the accuracy and feasibility of use of various body composition measurement tools to assess body composition and conduct field-based research in backcountry hikers. This information can provide outdoor programs (eg, NOLS, Outward Bound, university outdoor programs) a reference point in maintaining the well-being of participants, aid in further understanding which tool would best fit unique backcountry settings for future scientific endeavors, and provide an internal programmatic assessment of body composition to ensure participants' energy requirements are met.

\section{Methods}

\section{STUDY DESIGN}

The study compared 3 body composition measurement tools: 1) The Tanita scale; 2) Harpenden skinfold calipers; and 3) the Bod Pod. The data collected from the Tanita scale and Harpenden skinfold calipers were compared against the data from the Bod Pod and assessed for field 
application. For the purposes of this study, the Bod Pod was used as a standard against which the skinfold calipers and Tanita scale were compared.

\section{PARTICIPANTS}

To maintain the homogeneity of the sample, participants were recruited from NOLS courses with the following expedition characteristics: participants had to be $>18$ y old, courses had to occur in the same region (ie, Rocky Mountain region) and be of the same length ( $23 \mathrm{~d}$ ), and participants had to be engaged in the same type of activity (ie, backpacking) with the same curricular purpose (ie, outdoor educator course). The final sample consisted of 22 NOLS students. The sample was $55 \%$ male $(\mathrm{n}=12)$ and $45 \%$ female $(n=10)$, with body mass index (BMI) of $23.7 \pm 4.1$ $\mathrm{kg} \cdot \mathrm{m}^{-2}$. Age was $26.1 \pm 10.3(18-55)$ y. While on expedition, all participants lived outdoors and were responsible for carrying their own food, clothing, and gear and cooking their own meals. This study was approved by the institutional review board of Weber State University in Ogden, UT. All participants gave written informed consent before the start of data collection.

\section{DATA COLLECTION}

Data collection took place before and after the expedition between 0600 and 0900. Pre-expedition measurements were collected at the Wyss Wilderness Medicine campus outside of Lander, WY, and postexpedition measurements were collected at the NOLS headquarters in Lander, WY. All body composition measurements were collected by a single technician. Height, weight, and body composition measurements were recorded before participants had their first meal of the day. Pre- and post-trip anthropometric measures were collected from each participant using 3 body composition measurement tools: 1) Tanita BC-558 IRONMAN segmental body composition monitor (Tanita Corporation, Arlington Heights, IL); 2) Harpenden skinfold calipers (Baty International, Burgess Hill, West Sussex, UK); and 3) Bod Pod (COSMED USA Inc., Concord, CA). Women wore tight-fitting tops or sports bras, and all participants wore tight-fitting shorts while undergoing body composition measurements. Those with long hair wore swim caps while in the Bod Pod. Height was measured to the nearest half-inch using a cloth tape while participants stood with feet together and stretching upward. Skinfold thickness was measured to the nearest $0.1 \mathrm{~mm}$ at the triceps, suprailiac, and thigh on females and the pectoral, abdomen, and thigh on males. All measurements were collected on the right side of subjects' bodies. Body fat was calculated using the American College of Sports Medicine's 3-site formula. ${ }^{16}$

\section{STATISTICAL ANALYSIS}

Changes in body composition measured by the Bod Pod were determined using paired 2-sample $t$ tests, and influence of sex on body composition changes was assessed using analysis of covariance. To determine if pre-expedition body weight influenced changes in weight, regression analysis was used. Intraclass correlation coefficients were calculated to assess the degree of reliability between different measurement tools, and a paired $t$ test was used to determine the measurement bias, which is the consistent over or under measuring of a value by a measurement tool. Finally, the Bland-Altman method was used to assess the agreement of fat content measurements with the Bod Pod vs BIA and the Bod Pod vs skinfold. Statistical significance was accepted at $P<0.05$. Data are presented as mean \pm SD with range, as appropriate. Excel version 16.0 (Microsoft Corporation, Redmond, WA) and SPSS version 24 (SPSS Inc, Chicago, IL) were used to perform all statistical calculations.

\section{Results}

\section{CHANGES IN BODY COMPOSITION}

Participants lost a significant amount of weight, $1.8 \pm 3.0$ $\mathrm{kg}$, during the expedition (Table 1). Additionally, pre-expedition weight had a significant effect on weight loss $(\mathrm{F}=$ $14.199, P=0.001$ eta $^{2}=0.428$ ), with those participants at a higher pre-expedition weight losing more mass overall (Figure 1). On average, males and females did not differ in how much weight they lost $(P=0.8)$, and the effect of pre-expedition weight on weight loss is the same between sexes (data not shown). Fat mass significantly decreased by $2 \pm 10 \%(P=0.001)$, or $2.1 \mathrm{~kg}$. On average, males and females did not differ in how much fat they lost $(P=0.4)$, and the effect of pre-expedition weight on fat loss is the same between sexes (data not shown). Fat free mass increased by $0.4 \pm 1.9 \mathrm{~kg}$, but this did not reach significance $(P=0.9)$.

Table 1. Descriptive statistics for participants: age, weight, body mass index, fat mass, and lean mass from pre-expedition to postexpedition

\begin{tabular}{lllll}
\hline Characteristics & Pre & & Post & P value \\
\cline { 2 - 2 } & Mean $\pm S D$ & & Mean $\pm S D$ & \\
\hline Age $(\mathrm{y})$ & $26.1 \pm 10.3$ & & $26.1 \pm 10.3$ & \\
Weight $(\mathrm{kg})$ & $76.6 \pm 17.7$ & & $74.8 \pm 15.8^{a}$ & 0.01 \\
$\begin{array}{c}\text { Body mass index } \\
\quad\left(\mathrm{kg} \cdot \mathrm{m}^{-2}\right)\end{array}$ & $23.6 \pm 4.1$ & & $23.1 \pm 3.4^{a}$ & 0.01 \\
Fat mass $(\%)$ & $21.0 \pm 10.4$ & & $19 \pm 10.2^{a}$ & 0.001 \\
Lean mass $(\mathrm{kg})$ & $59.9 \pm 12.1$ & & $60.1 \pm 12.2$ & 0.91 \\
\hline
\end{tabular}

${ }^{a}$ Indicates a significant difference between pre and post measurements. 


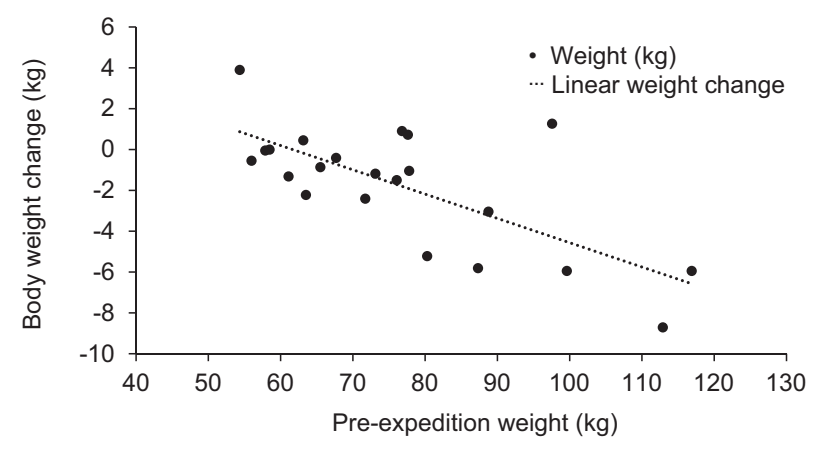

Figure 1. Effect of pre-expedition weight on weight loss for all participants. $\left(\mathrm{F}=14.199, P=0.001\right.$, eta $\left.{ }^{2}=0.428\right)$

\section{DIFFERENCES FOUND AMONG BODY COMPOSITION MEASUREMENT TOOLS}

A high degree of reliability was found between skinfold calipers and the Bod Pod and between BIA and the Bod Pod (Table 2). The average intraclass correlation coefficient between skinfolds and the Bod Pod was 0.95 with a $95 \%$ confidence interval from 0.87 to $0.98(\mathrm{~F}(21,21)=19.1$, $P<0.001)$ pre-expedition and was 0.95 with a $95 \%$ confidence interval from 0.87 to $0.98(\mathrm{~F}(21,21)=19.1$, $P<0.001)$ postexpedition. The average intraclass correlation coefficient between BIA and the Bod Pod was 0.95 with a $95 \%$ confidence interval from 0.88 to $0.98(\mathrm{~F}(21$, $21)=21.4, P<0.001)$ pre-expedition and was 0.95 with a $95 \%$ confidence interval from 0.89 to $0.98(\mathrm{~F}(21,21)=$ 21.6, $P<0.001)$ postexpedition. The BIA measurements significantly underreported body fat percentage when compared to the Bod Pod (pre-expedition $-2.1 \pm 3.9 \%$, $P=0.01$; postexpedition $-2.1 \pm 3.8 \%, P=0.01$ ), whereas the skinfold measurements were not significantly different from the Bod Pod (pre-expedition $=0.9 \pm 4.4 \%, P=0.3$; postexpedition $0.3 \pm 4.3 \%, P=0.7$ ). Correlation results between the Bod Pod vs BIA and the Bod Pod vs skinfold can be seen in Figures 2 and 3, respectively.

The Bland-Altman plots for the measurement comparisons are shown in Figures 4 and 5. The analysis displayed wide limits of agreement between all methods, with the widest seen between the Bod Pod and skinfold measurements (range $=17.3$ and $16.7 \%$ pre- and postexpedition, respectively). Pearson's correlation coefficient, measurement bias, standard deviation of the bias, limits of agreement, and $P$ value for each comparison are listed in Table 3 .

\section{Discussion}

Participation in outdoor activities has increased steadily in the past decade, with hiking being the third most popular outdoor activity for adults $>25$ y old. ${ }^{17}$ More than 10 million adults participated in backpacking in the United States in 2015. ${ }^{17}$ Backpackers face a unique challenge in trying to meet adequate energy requirements while in the backcountry. Energy deficit while in the backcountry is dangerous and could result in health and safety risks including but not limited to loss of coordination, collapse, and dehydration. Given the rise in popularity, there is a critical need to understand the energy requirements of this specific population. Our findings provide backpackers, and specifically outdoor programs that run multiweek backpacking expeditions (eg, NOLS, Outward Bound, university outdoor programs), data that can support administrators and instructors in making informed programmatic and risk

Table 2. Intraclass correlation results for Bod Pod vs skinfold and Bod Pod vs BIA

\begin{tabular}{|c|c|c|c|c|c|c|c|c|}
\hline & & \multirow[t]{2}{*}{ Intraclass correlation } & \multicolumn{2}{|c|}{$95 \%$ confidence interval } & \multicolumn{4}{|c|}{$F$ test with true value 0} \\
\hline & & & Lower bound & Upper bound & Value & $d f 1$ & $d f 2$ & Sig \\
\hline & Bod Pod vs skinfold & & & & & & & \\
\hline Pre & Average measures & 0.948 & 0.874 & 0.978 & 19.082 & 21 & 21 & $<0.001$ \\
\hline \multirow[t]{2}{*}{ Post } & Average measures & 0.948 & 0.874 & 0.978 & 19.113 & 21 & 21 & $<0.001$ \\
\hline & Bod Pod vs BIA & & & & & & & \\
\hline Pre & Average measures & 0.953 & 0.887 & 0.981 & 21.365 & 21 & 21 & $<0.001$ \\
\hline Post & Average measures & 0.954 & 0.888 & 0.981 & 21.556 & 21 & 21 & $<0.001$ \\
\hline
\end{tabular}

BIA, bioelectrical impedance. 

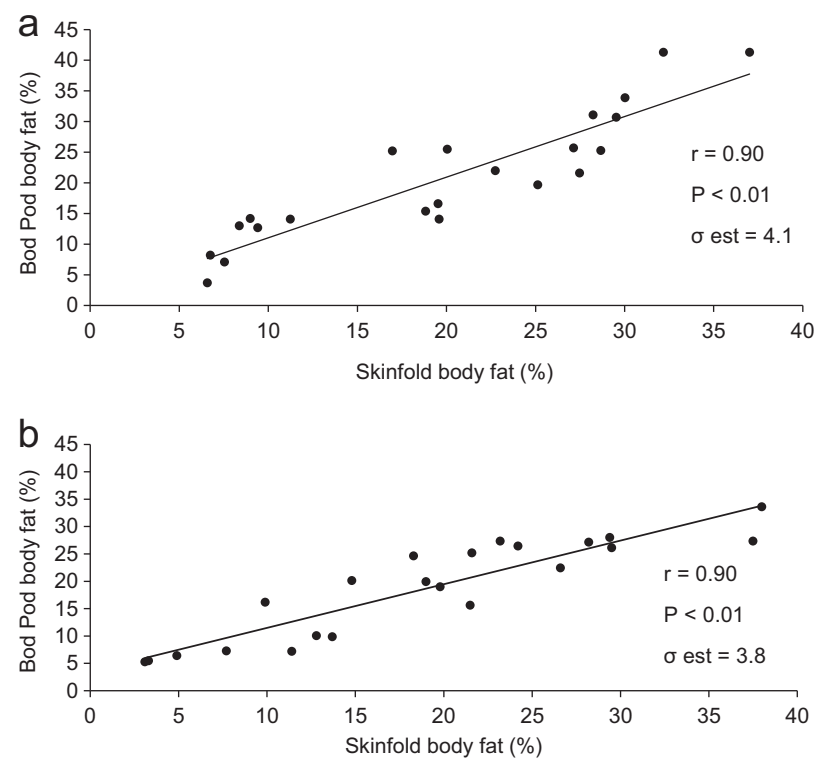

Figure 2. A, Correlation results for Bod Pod vs skinfold pre-expedition. B, Correlation results for Bod Pod vs skinfold postexpedition.

management decisions that can influence changes in participants' body composition.

In terms of body composition changes in this group, average weight loss was $1.8 \pm 3.0 \mathrm{~kg}$ during the course of the 23-d expedition, which is equivalent to $\pm 1 \mathrm{lb} \cdot \mathrm{wk}^{-1}$. We do not believe this weight loss poses a significant risk to NOLS participants and therefore do not recommend any alterations to NOLS's current rationing system. Previous studies of NOLS participants have reported acceptable dietary macronutrient distribution ranges of 52 to $59 \%$ of calories derived from carbohydrate, 31 to $35 \%$ of calories derived from fat, and 11 to $13 \%$ of calories derived from protein. ${ }^{5,18}$ However, additional examination of protein and carbohydrate intake to attenuate loss of weight and fat-free mass in backcountry athletes may be warranted. ${ }^{5}$

Regarding the influence of sex and pre-expedition weight on changes in body composition, males and females
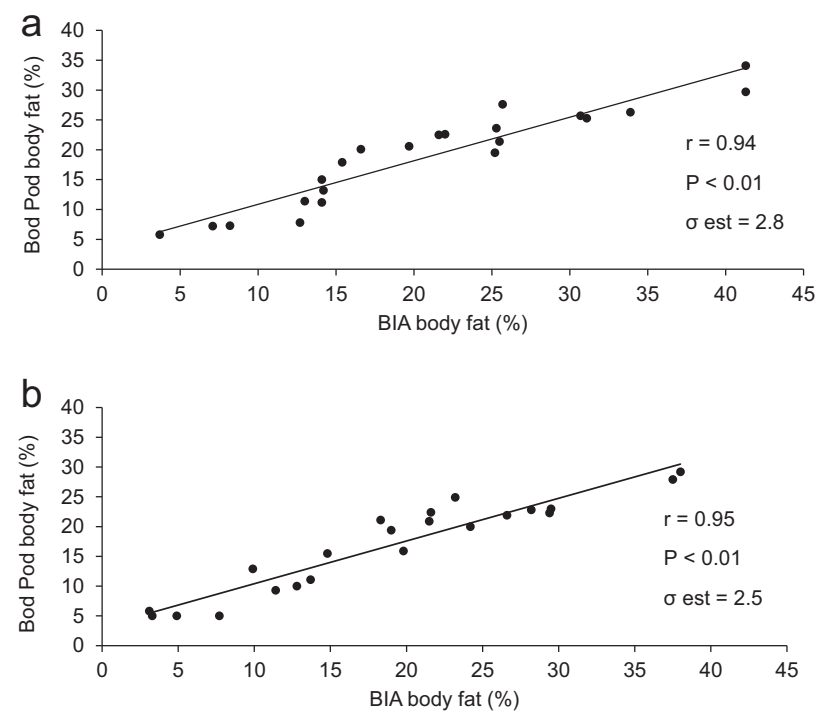

Figure 3. A, Correlation results for Bod Pod vs bioelectrical impedance (BIA) pre-expedition. B, Correlation results for Bod Pod vs BIA postexpedition. 

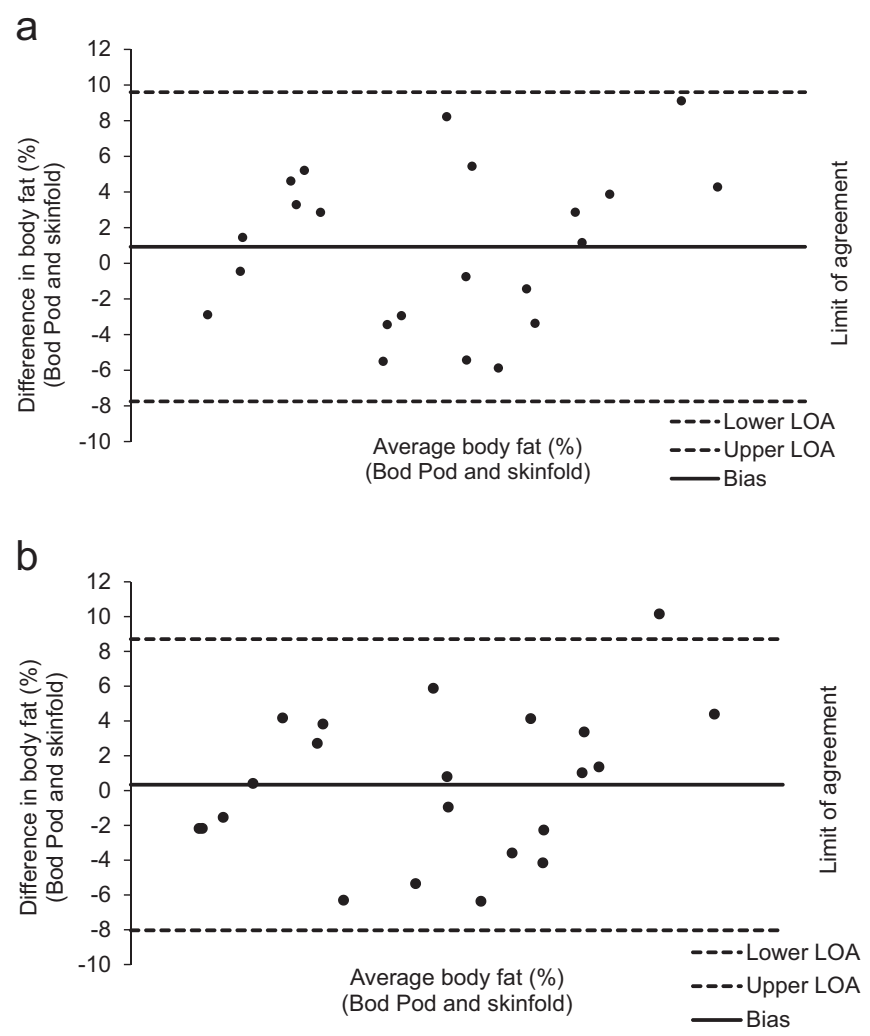

Figure 4. A, Bod Pod vs skinfold Bland-Altman plot of pre-expedition body fat percentage. B, Bod Pod vs skinfold Bland-Altman plot of postexpedition body fat percentage. The middle line represents the mean of the 2 techniques. The upper and lower dashed lines represent the $95 \%$ limits of agreement or 1.96 standard deviations of the difference.

did not significantly differ in their weight or fat loss, but pre-expedition weight did have a significant effect on weight loss overall. Participants starting the expedition at a higher weight lost more weight by the end of the expedition than those starting at a lower weight. Although initial tests signified a difference in average weight loss between males and females, this was explained when accounting for pre-expedition weight. Forty percent of the male participants began the expedition at a BMI that would classify them as overweight or obese, whereas only $10 \%$ of the females were classified at an overweight BMI (data not shown). Although sex was not an influencing factor in this study, there does seem to be some relationship between sex and body weight in this population, as indicating by the higher pre-expedition BMI in males. However, this relationship is beyond the scope of this study. Future research efforts may be warranted to disentangle this relationship.

Studying changes in body composition of backcountry hikers is important in determining the feasibility and accuracy of body composition measurement tools for use in the field. NOLS has developed a compendium of studies using various body composition measurement tools, including the Bod Pod, BIA, and skinfold calipers, but the ability to draw conclusions from their collected data relies on the validity and comparability of these measurement tools.

BIA and skinfolds are popular methods to measure body composition because both are quick, safe, affordable, and portable, but the accuracy of each method is affected by a number of factors. The accuracy of BIA is affected by hydration status and extremely high or low body mass index, and the accuracy of skinfold calipers depends on amount of adipose tissue, fat patterning, and compressibility of skinfolds. ${ }^{11,12}$ Variability can also be found among anthropometrists' measurements because administration of the skinfold test requires proper training. ${ }^{19}$ Additionally, the make of the caliper can affect the accuracy of the measurement. The Harpenden caliper consistently yields lower values when compared to the Lange caliper. ${ }^{20}$ The Bod Pod, however, is a quick, comfortable, noninvasive technique to measure body composition, but it is cumbersome to transport, expensive to maintain, requires special clothing to use, and in general lacks the ability to be used in fieldbased research. Because of its cost, the Bod Pod is often 

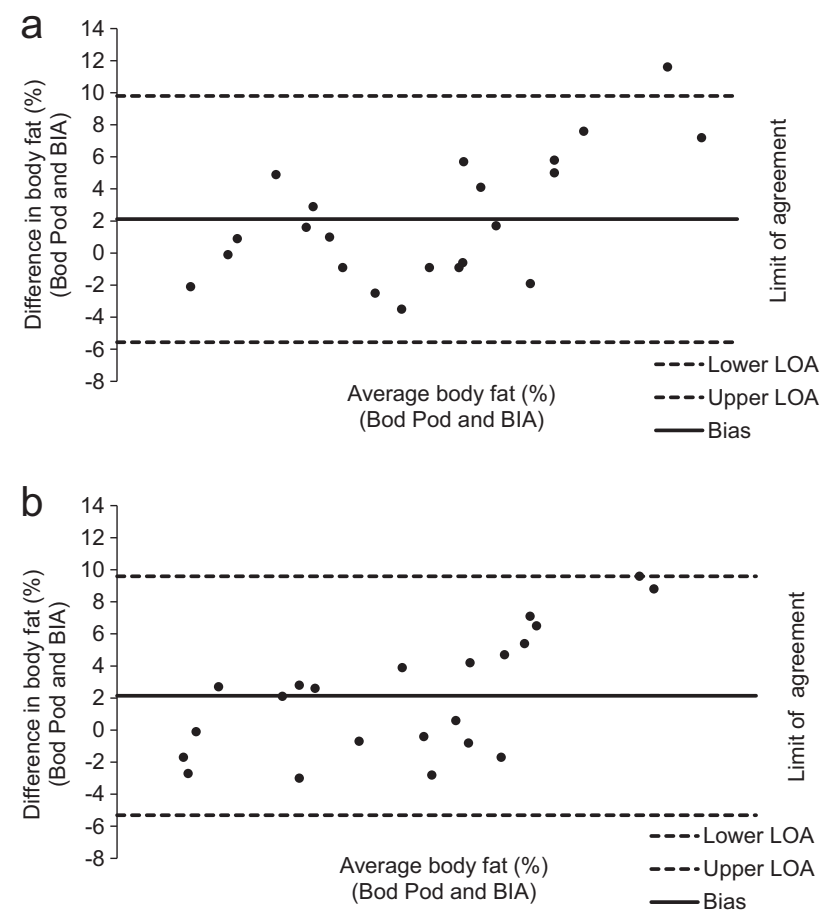

Figure 5. A, Bod Pod vs bioelectrical impedance (BIA) Bland-Altman plot of pre-expedition body fat percentage. B, Bod Pod vs BIA Bland-Altman plot of postexpedition body fat percentage. The middle line represents the mean of the 2 techniques. The upper and lower dashed lines represent the $95 \%$ limits of agreement or 1.96 standard deviations of the difference.

reserved for use in academic or clinical settings. ${ }^{15}$ Research suggests that the Bod Pod provides reliable and valid estimates of body composition when compared to other body composition reference methods, so it was chosen as the standard measurement in this study. 7,13

Our findings indicate that although there was a high degree of reliability between skinfold calipers and the Bod Pod and between the Tanita scale and the Bod Pod, the Tanita scale consistently underreported body fat percentage by $2.1 \%$, indicating a significant measurement bias. This is consistent with previous research that found that leg-to-leg BIA significantly underreported body fat percentage in a group of collegiate wrestlers when compared to both the Bod Pod and hydrostatic weighing. ${ }^{6}$ However, this significance may be in part explained by the use of a BIA system with only 2 points of contact.

On the other hand, although the average measurements from the skinfold calipers did not significantly differ from the Bod Pod, there was more variability in the measurement, with some measurements being higher and some lower than those of the Bod Pod (pre-expedition $0.9 \pm 4.4 \%$ and postexpedition $0.3 \pm 4.3 \%$ ). Given the purposes of NOLS's research interest, to track body composition changes, the tool that offers the most consistent measurements, regardless

Table 3. Comparisons of body fat percentage from the Bod Pod, BIA, and skinfold techniques

\begin{tabular}{lcclc}
\hline & $r$ & Bias $\pm S D(\%)$ & Limits of agreement $(\%)$ & P value \\
\hline Pre-expedition & & & & \\
Bod Pod-BIA & 0.94 & $2.1 \pm 3.9$ & $-5.6,9.8$ & 0.01 \\
Bod Pod-Skinfold & 0.90 & $0.9 \pm 4.4$ & $-7.7,9.6$ & 0.30 \\
Postexpedition & & & & \\
Bod Pod-BIA & 0.95 & $2.1 \pm 3.8$ & $-5.3,9.6$ & 0.01 \\
Bod Pod-Skinfold & 0.90 & $0.3 \pm 4.3$ & $-8.0,8.7$ & 0.70 \\
\hline
\end{tabular}

BIA, bioelectrical impedance. 
of measurement bias, will be best for use in measuring changes across time. Thus, the consistency of reporting and the narrower limits of agreement that the Tanita scale offered are desirable. Considering the skinfold caliper test also requires training to administer, this might suggest that the Tanita scale is a more desirable tool for field-based programs, although the authors acknowledge that programmatic goals vary with each institution and each study.

\section{LIMITATIONS}

The present study has several limitations. First, the only accurate method of measuring body composition is cadaver analysis, although in vivo models such as air or water displacement plethysmography have been widely accepted as reference methods. ${ }^{7,13,14}$ Still, these reference methods are mere estimations of body composition and suffer both methodologic and biologic error. Body composition measurements from the Bod Pod rest on the assumption that the density of lean mass is constant from person to person and that subjects only vary from the standard in their amount of body fat. ${ }^{21}$ Deviations from these basic assumptions are likely to occur owing to variations in hydration status. If a subject is overhydrated, the Bod Pod would likely underestimate fat free mass because of a lower lean mass density. Because BIA measurements are also affected by hydration status, a second limitation of this study is that hydration was not measured via urinalysis. In an attempt to minimize these potential effects, body composition was measured first thing in the morning, before participants ate, drank, showered, or exercised. Still, the authors acknowledge that this population is subject to dramatic changes in hydration status given the length and nature of their expedition. Finally, in light of the small sample size of this study, data should be viewed as preliminary.

\section{Conclusions}

This study is part of a larger effort to accurately assess the body composition changes that occur in the backcountry and will ultimately assist in maintaining the health and safety of participants in outdoor programs that conduct multiweek backpacking expeditions. Although the accuracy of various body composition measurement modalities is well established, no research to our knowledge exists that compares the use of these methods on outdoor recreation participants. This study suggests that the skinfold caliper and the Tanita scale give measurements comparable to that of the less readily available and more costly lab-based Bod Pod measurement in backcountry expedition participants. Thus, the use of these tools can provide outdoor programs with valid measurements that can be used as a reference point to help ensure participants are adequately meeting energy requirements.

Author Contributions: Data acquisition, data analysis, drafting of the manuscript (JB); study concept and design, data acquisition, critical revision of manuscript (MM); study concept and design, data acquisition (CM); data acquisition (TR); data acquisition (SR).

Financial/Material Support: Funding provided by the National Outdoor Leadership School (NOLS) and Weber State University.

Disclosure: None.

\section{References}

1. National Outdoor Leadership School. About NOLS. Available at: https://www.nols.edu/en/about/. Accessed April 10, 2016.

2. Pearson C, Lindholm C. NOLS Cookery. 5th ed. Mechanicsburg, PA: Stackpole Books; 2003.

3. Pohja M, Ocobock C, Gookin J. Energy expenditure in the backcountry. Res Outdoor Educ. 2014;12:99-115.

4. National Outdoor Leadership School. Risk management at the National Outdoor Leadership School. Available at: https:// www.nols.edu/media/filer_public/54/af/54afe79e-7796-4a8f82ef-468cdf30be86/risk-management-at-nols-2018.pdf. Accessed September 21, 2018.

5. Morgan C, Masters M, Rochelle S, Ruden T, Gookin J. Energy balance: assessing dietary intake and changes in body composition during National Outdoor Leadership School expeditions. J Outdoor Recreat Educ Leadersh. 2017;9(4):363-76.

6. Dixon CB, Deitrick RW, Pierce JR, Cutrufello PT, Drapeau L. Evaluation of the BOD POD and leg-to-leg bioelectrical impedance analysis for estimating percent body fat in National Collegiate Athletic Association Division III collegiate wrestlers. J Strength Cond Res. 2005;19(1):85-91.

7. Parker L, Reilly JJ, Slater C, Wells JC, Pitsiladis Y. Validity of six field and laboratory methods for measurement of body composition in boys. Obesity. 2003;11(7):852-8.

8. Hetzler RK, Kimura IF, Haines K, Labotz M, Smith J. A comparison of bioelectrical impedance and skinfold measurements in determining minimum wrestling weights in high school wrestlers. J Athl Train. 2006;41(1):46-51.

9. Bracco D, Chiolero Thiebaud RL, Landry M, Burckhardt P, Schutz Y. Segmental body composition assessed by bioelectrical impedance analysis and DEXA in humans. J Appl Physiol. 1996;81(6):2580-7.

10. Kushner RF. Bioelectrical impedance analysis: a review of principles and applications. J Am Coll Nutr. 1992;11(2): 199-209.

11. Kylea UG, Bosaeusb I, Lorenzoc AD, et al. Bioelectrical impedance analysis - part 1: a review of principles and methods. Clin Nutr. 2004;23(5):1226-43.

12. Norton K, Olds T. Anthropometrica: A Textbook of Body Measurement for Sports and Health Courses. Sydney, Australia: UNSW Press; 1996.

13. Heyward V. ASEP methods recommendation: body composition assessment. J Exerc Physiol Online. 2001;4(4): $1-12$. 
14. Wells JCK, Fewtrell MS. Measuring body composition. Arch Dis Child. 2006;91(7):612-7.

15. Fields DA, Goran MI, McCrory MA. Body composition assessment via air displacement plethysmography in adults and children: a review. Am J Clin Nutr. 2002;75(3):453-67.

16. American College of Sports Medicine. ACSM's Guidelines For Exercise Testing and Prescription. 9th ed. Philadelphia, PA: Lippincott Williams \& Wilkins; 2013.

17. The Outdoor Foundation. Outdoor Recreation Participation Topline Report 2016. Available at: https://outdoorindustry. org/wp-content/uploads/2017/05/2016-Topline-Report.pdf. Accessed January 14, 2019.
18. Ryan M. Backcountry Nutrition. Mechanicsburg, PA: Stackpole Books; 2008.

19. Lohman TG, Pollock ML. Skinfold measurement: which caliper? How much training? J Phys Educ Recreat. 1981;52(1): 27-9.

20. Gruber JJ, Pollock ML, Graves JE, Colvin AB, Braith RW. Comparison of Harpenden and Lange calipers in predicting body composition. Res Q Exerc Sport. 1990;61(2):184-90.

21. Hames KC, Anthony SJ, Thornton JC, Gallagher D, Goodpaster BH. Body composition analyses by air displacement plethysmography in adults ranging from normal weight to extremely obese. Obesity. 2014;22(4):1078-84. 